
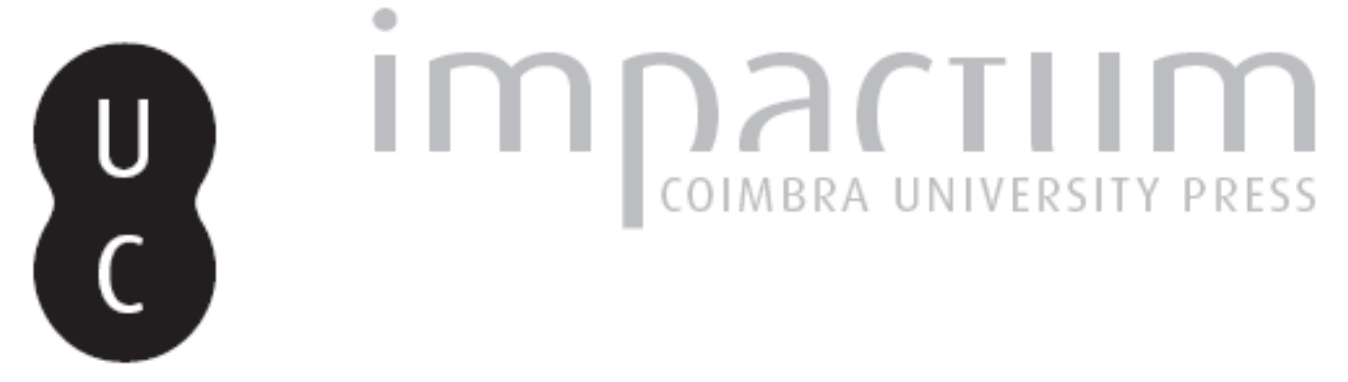

\title{
A legitimidade da democracia na América Latina
}

Autor(es): $\quad$ Lopes Salles, Denise Mercedes Núñez Nascimento

Publicado por: Universidade Católica de Petrópolis

URL persistente:

URI:http://hdl.handle.net/10316.2/33744

DOI:

DOI:http://dx.doi.org/10.14195/2175-0947_4-2_4

Accessed : $\quad$ 26-Apr-2023 14:54:44

A navegação consulta e descarregamento dos títulos inseridos nas Bibliotecas Digitais UC Digitalis, UC Pombalina e UC Impactum, pressupõem a aceitação plena e sem reservas dos Termos e Condições de Uso destas Bibliotecas Digitais, disponíveis em https://digitalis.uc.pt/pt-pt/termos.

Conforme exposto nos referidos Termos e Condições de Uso, o descarregamento de títulos de acesso restrito requer uma licença válida de autorização devendo o utilizador aceder ao(s) documento(s) a partir de um endereço de IP da instituição detentora da supramencionada licença.

Ao utilizador é apenas permitido o descarregamento para uso pessoal, pelo que o emprego do(s) título(s) descarregado(s) para outro fim, designadamente comercial, carece de autorização do respetivo autor ou editor da obra.

Na medida em que todas as obras da UC Digitalis se encontram protegidas pelo Código do Direito de Autor e Direitos Conexos e demais legislação aplicável, toda a cópia, parcial ou total, deste documento, nos casos em que é legalmente admitida, deverá conter ou fazer-se acompanhar por este aviso.

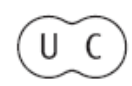



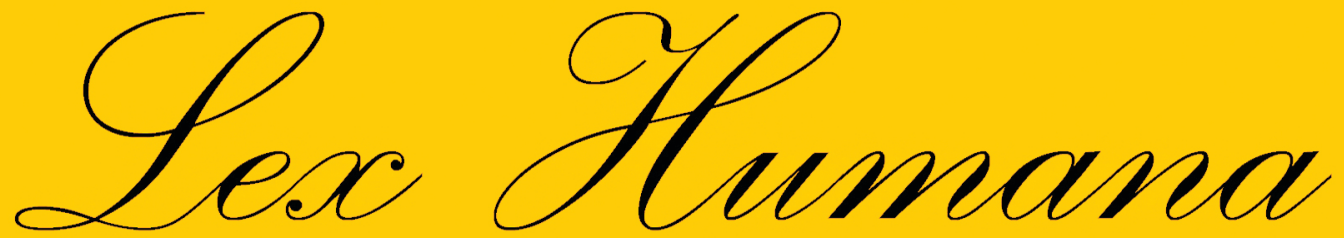

Revista do Programa de Pós-Graduação em Direito da UCP

ISSN(e) 2175-0947

Universidade Católica de Petrópolis Rua Benjamin Constant, 213 - Petrópolis - Centro CEP 25610-130

Tel: (24) 2244-4000 E-mail: lexhumana@ucp.br 


\section{A LEGITIMIDADE DA DEMOCRACIA NA AMÉRICA LATINA*}

\section{THE LEGITIMACY OF DEMOCRACY IN LATIN AMERICA *}

\section{DENISE MERCEDES NÚÑEZ NASCIMENTO LOPES SALLES ${ }^{* * *}$ UNIVERSIDADE CATÓLICA DE PETRÓPOLIS, BRASIL}

Resumo: Analisamos a legitimidade política da democracia na América Latina com dados do Latinobarômetro, survey de atitudes e valores que vem sendo aplicado anualmente desde $1996 \mathrm{em}$ 18 países da região, em dois eixos: um metodológico e outro teórico. Por um lado, contribuímos para a verificação empírica do conceito e de suas diferentes operacionalizações, alinhando nossos resultados ao debate mais amplo. E, no campo teórico, os nossos resultados nos permitem ampliar o debate sobre a relação entre legitimidade e estabilidade democrática.

Palavras-chave: Legitimidade; confiança política; cultura política; democracia na América Latina.

Abstract: We have analyzed the political legitimacy of democracy in Latin America with Latinobarometro's data, which is a survey about attitudes and values that has been applied annually since 1996 in 18 countries of the region, in two axes: one methodological and the other theoretical. On the one hand, we contribute to the empirical validation of the concept and its differents operationalizations, while aligning our results to the wider debate. And, in the theoretical field, our results allow us to broaden the debate on the relationship between legitimacy and democratic stability.

Keywords: Legitimacy; political trust; political culture; democracy in Latin America.

\footnotetext{
* Esse texto foi resultado da pesquisa acadêmica realizada durante a disciplina América Latina: uma informação sobre sua História ministrada pelo Prof. Gláucio Soares no programa de doutorado do Instituto Universitário de Pesquisas do Rio de Janeiro (IUPERJ), Brasil.

* $\quad$ Artigo recebido em 01/10/2012 e aprovado para publicação pelo Conselho Editorial em 05/12/2012.

** Doutora em Ciência Política pelo Instituto de Estudos Sociais e Políticos da Universidade Estadual do Rio de Janeiro, Brasil. Mestre em Ciência Política pelo Instituto Universitário de Pesquisas do Rio de Janeiro. Professorada Universidade Católica de Petrópolis, Brasil. Currículo Lattes: http://lattes.cnpq.br/1594102305404307.E-mail: denise.salles@,ucp.br.
} 


\section{Introdução}

Em 1963 Gabriel Almond e Sidney Verba concluíram em estudo sobre os EUA que haveria uma relação necessária entre cultura cívica e desenvolvimento democrático (cf. ALMOND, G. \& VERBA, S., 1965). Invertendo a lógica da análise política dominante até então, Almond e Verba afirmaram a importância das orientações subjetivas dos cidadãos e assim da cultura política de um país para o seu desenvolvimento político institucional. Desde então os estudos sobre a cultura política e sua importância para a democracia tem crescido em proporção semelhante a dos surveys de atitudes e valores, que se estenderam para além dos países centrais, possibilitando um conhecimento mais aprofundado sobre o tema.

Muitas análises enfatizaram a tendência de queda da confiança nas instituições públicas nos países centrais e as possíveis consequências para o sistema político (cf. NYE \& ZELIKOW, 1997; KINGLEMAN \& FUCHS, 1997; PHAR \& PUTNAM, 2000). Os pesquisadores variam em seus diagnósticos desde os mais pessimistas que indicam as possibilidades iminentes de quebras na democracia e os menos drásticos que sustentam a existência de democracias com qualidade inferior de acordo com o envolvimento dos cidadãos na vida política. Atualmente este é um dos problemas centrais para quem se dedica ao estudo da cultura política: o aparente paradoxo entre a erosão da confiança nas instituições políticas e a falta de efeitos drásticos no mundo político, ou seja, falta de quebras da democracia tais como revoluções ou guerras civis.

Recentemente, muitos pesquisadores interessados no tema da crescente desconfiança retomaram o trabalho pioneiro de David Easton e sua teorização da legitimidade como apoio político. De acordo com Easton o apoio político seria subdividido em apoio difuso (subdividido em atitudes em relação à comunidade política e as voltadas para o regime) e apoio específico (em relação ao desempenho das autoridades). Nesta visão a legitimidade política é um conceito multidimensional, onde cada dimensão possui determinantes próprios. O apoio difuso seria moldado pelas experiências pessoais dos cidadãos, ideologias e socialização, enquanto que o apoio específico seria mais conjuntural e dependeria das avaliações da performance das autoridades e instituições. 
Aliada à perspectiva de Seymor Martin Lipset ${ }^{1}$, a teoria da legitimidade previa que o longo processo histórico de democratização e a estabilidade democrática (países centrais) levariam necessariamente a altos níveis de legitimidade política. Entretanto, de formas diversas esta teoria vem sendo contestada ${ }^{2}$ e o papel real da legitimidade política em nossas sociedades ainda não está claro. Por um lado, os partidários da teoria afirmam a existência de um "reservatório de apoio" (apoio difuso aos princípios do regime democrático) que manteria o regime funcionando. Por outro, os críticos tratam do paradoxo entre a desconfiança e a ausência de quebras do regime como argumento da não importância da cultura política como variável explicativa da realidade política.

Nesta análise pretendemos seguir a perspectiva mais recente de estudo da legitimidade política (cf. SELIGSON, BOOTH \& GÓMEZ, 2006; MOISÉS, 2005; DALTON, 2004; NORRIS, 1999) trazendo o debate para o caso latino-americano. Como alguns autores têm chamado atenção (MOISÉS, 2005; RENNÓ, 2001), nota-se a partir de surveys atitudinais dos cidadãos latino-americanos um descompasso entre a valorização da democracia enquanto ideal e a satisfação com o funcionamento das democracias reais. Assim, enquanto a democracia como ideal tem amplo apoio, há uma crescente desconfiança e descrença das autoridades e das instituições políticas democráticas. No longo prazo a questão que permanece é: poderá a democracia na América Latina consolidar-se com baixos níveis de apoio político específico? Ou seja, o apoio político difuso é suficiente para o bom funcionamento das democracias latino-americanas?

O nosso propósito é analisar a legitimidade política da democracia na América Latina com dados do Latinobarômetro, tendo dois eixos principais: um metodológico e outro teórico. No campo metodológico importa ainda verificar a existência empírica do conceito e de suas diferentes operacionalizações. Além disso, importa testar a validade de uma das mais importantes pesquisas multinacionais que nos oferecem dados sobre a América Latina: o Latinobarômetro, survey de atitudes e valores que vem sendo aplicado anualmente desde $1996 \mathrm{em}$ 18 países da região.

No campo teórico, acreditamos ser importante definir de que forma se correlacionam a dimensão difusa e específica da legitimidade para futuramente testar quais são os determinantes de cada uma destas facetas do apoio político. Acreditamos que este é um passo

\footnotetext{
${ }^{1}$ De acordo com Lipset, o processo histórico de democratização indicava que, após a superação das crises, os regimes entravam em uma ampla estabilidade com forte legitimidade política.

${ }^{2}$ Glaucio Soares (1987), por exemplo, mostrou que a relação prevista entre desenvolvimento econômico e democracia não se aplica no caso latino-americano.
} 
importante para pesquisas futuras que queiram tratar da relação entre legitimidade e estabilidade democrática.

\section{O olhar empírico sobre a Legitimidade Política}

O tema da legitimidade e sua real importância para a estabilidade e o funcionamento da democracia foi tratado por diversos pesquisadores nos últimos anos. Para o nosso propósito aqui ${ }^{3}$, importa salientar as contribuições de Mitchell Seligson, John Booth e Miguel Goméz e de José Álvaro Moisés que se debruçaram sobre dados da América Latina. Paralelamente, os trabalhos de Pippa Norris, Russel Dalton e Hans-DieterKingleman sobre os países centrais serão usados aqui como meio para o debate.

Em Critical Citizens, Norris e seus colaboradores ${ }^{4}$ estudaram o declínio da confiança nas instituições políticas retomando o framework definido por Easton para tratar do apoio político. De acordo com Norris, tratar apenas da queda na confiança política não nos leva a uma compreensão global do fenômeno, uma vez que o apoio político é multidimensional, sendo a confiança em instituições políticas apenas uma das dimensões. Norris acrescentou novas dimensões à perspectiva de Easton (que distinguia o apoio à comunidade, ao regime, às autoridades, sendo esta última o apoio específico e as duas primeiras o apoio difuso). De acordo com Norris e seus colaboradores (1999, p. 1-27) a legitimidade tem cinco componentes: Comunidade Política (nação), Princípios do regime (valores centrais do sistema político), Desempenho do regime (funcionamento do regime na prática), Instituições do regime (instituições existentes de governo) e Atores políticos.

Estes componentes variam do mais difuso (comunidade política) ao mais específico (atores políticos). Além disso, é de se esperar maiores níveis de apoio nas dimensões mais difusas do que nas específicas. Esta foi a constatação feita por diversos dos pesquisadores envolvidos que trataram dos países centrais. Com isso, constata-se que a queda dos patamares de confiança política é generalizada, porém também o é a permanência de altas taxas de apoio difuso à democracia.

Com a distinção entre os componentes da legitimidade feita por Norris foi possível identificar que se em relação ao desempenho, às instituições e aos atores políticos os cidadãos

\footnotetext{
${ }^{3}$ Por razões de tempo e espaço não é possível aqui destacar diversas outras contribuições ao debate sobre a legitimidade.

4 O livro CriticalCitizens (1999) foi organizado por Pippa Norris e contém artigos de vários pesquisadores analisando contextos diferentes.
} 
estão insatisfeitos, em relação à democracia como valor a adesão permanece alta. Distinguir entre as dimensões de princípios do regime e desempenho do regime é fundamental para observar isso.

Deste diagnóstico podem derivar perspectivas quase opostas de entendimento do fenômeno. Os diversos pesquisadores envolvidos no projeto de Norris dividem-se entre aqueles que observam nisso o crescimento dos cidadãos críticos ou de democratas insatisfeitos, que têm fortes valores democráticos e avaliam como insuficiente o desempenho das instituições democráticas atuais demandando sua transformação para alguns em uma democracia mais participativa. Outros pesquisadores (especialmente aqueles que concentram suas análises nas novas democracias) acreditam que esta distância entre o apoio difuso e o específico deve ser olhada com cuidado, pois ela pode levar a quebras da democracia uma vez que os cidadãos não parecem estar comprometidos (ou satisfeitos) com o modo como as autoridades e as instituições estão atuando, o que possibilitaria a emergência de golpes em períodos de crises econômicas e políticas.

Diante do que está em jogo especialmente nos países de democratização mais recente (e com processos históricos bem diferentes dos países centrais) importa verificar um elemento central da teoria da legitimidade, qual seja o de que a existência de um reservatório de apoio (em termos de apoio difuso) seria suficiente para a estabilidade democrática. Duas questões são importantes aqui: por um lado interessa verificar se a operacionalização comumente feita para tratar dos cinco componentes da legitimidade é válida no nosso caso. Por outro, importa constatar também se os elementos associados ao apoio difuso e os associados ao apoio específico nos países centrais são os mesmos na América Latina.

Seligson, Booth e Gómez inserem-se neste debate analisando a América Latina e discutindo a validade metodológica e teórica da forma tradicional de se operacionalizar a legitimidade política democrática. Desde o trabalho de Easton a legitimidade vem sendo concebida por diversos autores como multidimensional, indo do apoio abstrato a uma comunidade política subjacente aos princípios do regime à avaliação mais concreta do desempenho do regime, das suas instituições e seus atores (DALTON, 2004; NORRIS, 1999; KLINENBERG, 1999). Para Seligson, entretanto, apesar do relativo consenso existente no campo teórico, não houve avanços no sentido de testar a validade empírica do constructo teórico da legitimidade de Easton. Assim, estes pesquisadores posicionam-se nesta lacuna a partir da análise de um survey feito na Costa Rica em 2002 desenhado para testar amplamente a validade empírica da legitimidade política. 
Verificar quais são e onde estão os efeitos do declínio da legitimidade e porque este declínio não tem levado a protestos mais generalizados contra o sistema é tarefa que só pode ser levada a cabo após uma correta operacionalização e mensuração do conceito de legitimidade política. Assim, Seligson et alli testam primeiro os componentes da legitimidade e sua dimensionalidade em cada contexto (país) antes de usar bases de dados com diversos países para evitar o problema da heterocedasticidade em bases de dados comparativas.

Estes autores também alertam que usar análise fatorial com rotação varimax para testar a dimensionalidade da legitimidade contradiz a teoria da legitimidade. Neste sentido, Seligson, Booth e Gomez criticam o trabalho de Dalton (2004) que usou análise fatorial com rotação varimax o que pressupõe a ortogonalidade dos fatores e não a inter-correlação como prevê a teoria. Seligson e outros usam Análise Fatorial Confirmatória - AFC (modelagem de equações estruturais) para testar a validade do constructo da legitimidade. Dalton realizou uma análise fatorial em uma amostra reunida multinacional que revelou quatro dimensões da legitimidade: apoio à comunidade, à democracia, às instituições e às autoridades.

Outro ponto que os autores chamam atenção é que o ideal seria usar múltiplos itens para cada dimensão, porém o alto custo dos surveys leva muitos pesquisadores a usar um item (pergunta do questionário) para mensurar apoio a cada dimensão.

Além disso, normalmente não é testada a importância da legitimidade do governo local. Entretanto, para os autores, "o governo local propicia um foro alternativo à política nacional" (SELIGSO, BOOTH \& GOMÈZ, 2006 , p. 10) e estudos têm demonstrado que apoio ao governo local conduz a engajamento. Seligson acredita que isso significa o início de uma explicação de porque o declínio do apoio público não levou a falência da democracia: os cidadãos críticos estariam voltando-se para foros de participação alternativos.

Por último, Seligson et alli criticam o uso de variáveis com a palavra democracia para medir o apoio aos princípios e ao desempenho do regime como recomenda Norris e Dalton testa em seu último trabalho. O uso do termo "democracia" tem, para Seligson, dois problemas: 1. "Desejabilidade social" enviesa as respostas no sentido democrático, e 2. Interpretações diversas do termo segundo o público que esteja sendo pesquisado: por exemplo, enquanto os costarriquenhos definem democracia em termos de liberdade, os chilenos a definem como capitalismo e livre empresa segundo pesquisa dos próprios autores. Assim, o melhor seria usar itens perguntando pelo cerne da democracia sem usar o termo: ou seja, perguntar pela aprovação da participação dos cidadãos na política. Entretanto, a maior parte dos surveys não tem perguntas como estas, e o ideal seria que contivesse as duas formas (a que os autores 
propõem e a que eles estão criticando) para que pudéssemos testar verdadeiramente se a "desejabilidade social" enviesa as respostas de apoio a valores democráticos e de satisfação com o funcionamento da democracia.

Para operacionalizar o desempenho do regime, Seligson e seus companheiros sugerem usar os itens sociotrópicos padrão sobre o desempenho da economia; uma vez que a economia é um fator crítico na avaliação que os cidadãos fazem do governo e estes itens existem em diversos surveys.

Os principais resultados da AFC de Seligson, Booth e Goméz são:

- Confirmação da multidimensionalidade da legitimidade: aqui equiparada a seis dimensões, quatro delas condizentes com a previsão de Norris: apoio a princípios do regime, desempenho do regime, instituições do regime, e atores políticos. As duas outras provém da divisão do apoio à instituições em duas: uma difusa (trata do funcionamento das instituições de forma mais generalizada) e outra específica (referida à varias instituições específicas). A última dimensão constitui-se da colaboração mais importante do trabalho de Seligson et alli: a mensuração do apoio ao governo local como um componente do apoio político;

- Fortes correlações entre as seguintes dimensões da legitimidade: apoio as instituições e apoio difuso as instituições $(0,89)$, apoio a instituições do regime e apoio a atores políticos $(0,63)$, apoio as instituições do regime e apoio ao governo local $(0,54)$ apoio difuso e apoio a atores políticos $(0,49)$;

- Irrelevância da dimensão comunidade como um componente separado da legitimidade sua invariabilidade interna (resultado a que também chegou Dalton);

- Confirmação da expectativa de maior apoio difuso (a comunidade e aos princípios do regime) e menor apoio específico (desempenho, instituições, poder local e atores), o que pode ser observado pelas médias apresentadas na tabela incluída aqui no anexo 1. 


\section{A legitimidade política na América Latina}

Usaremos a amostra completa do Latinobarômetro $2004^{5}$ para tentar identificar a validade do constructo teórico da legitimidade política. Inicialmente julgamos que é válida uma primeira exploração sobre os elementos que formam a legitimidade na América Latina. Posteriormente, seguindo a orientação de Seligson, Booth e Goméz, será importante testar os elementos constitutivos da legitimidade em cada país e as diferenças entre os países.

Nosso intuito é tentar operacionalizar o conceito de duas maneiras: a primeira utilizando como modelo a pesquisa recente de Seligson, Booth e Gómez na Costa Rica, e a segunda de acordo com as orientações teóricas de Pippa Norris e as operacionalizações de Dalton e Kingleman (NORRIS, 1999; KINGLEMAN apud NORRIS, 1999 e DALTON 2004). Nosso propósito central é verificar se existem possibilidades de complementação entre estas duas propostas para tratarmos do apoio político na América Latina.

A tabela 1 resume o modelo proposto para dialogar com Seligson et alli. As escalas de todas variáveis foram recodificadas para 0-100, o que permite uma melhor visualização sobre as médias.

\footnotetext{
${ }^{5}$ O Latinobarômetro é um Survey nacional anual baseado em amostras probabilísticas (na maior parte dos países) e amostras por cotas de idade e gênero das populações urbanas de 18 países latino-americanos que tem como modelo o Eurobarometer e vem sendo realizado desde 1995.
} 
Tabela 1

Dimensões da Legitimidade Política - Latinobarômetro

(baseadas em Seligson, Booth e Gómez)

\begin{tabular}{|c|c|c|c|}
\hline Objeto de apoio & Operacionalização da Variável & Média & $\begin{array}{l}\text { Desvio } \\
\text { Padrão }\end{array}$ \\
\hline Comunidade política & $\begin{array}{l}\text { Quão orgulhoso está você de ser (nacionalidade)? (escala } \\
\text { entre nada orgulhoso }=0 \text { e muito orgulhoso }=4 \text { ) }\end{array}$ & 85,82 & 23,07 \\
\hline $\begin{array}{l}\text { Princípios centrais do } \\
\text { regime }\end{array}$ & ( & - & - \\
\hline \multirow{4}{*}{$\begin{array}{l}\text { Desempenho do } \\
\text { Regime }\end{array}$} & $\begin{array}{l}\text { Como você classificaria em geral a situação econômica do } \\
\text { país? (escala entre } 0=\text { muito ruim e } 5=\text { muito boa) }\end{array}$ & 24,37 & 23,27 \\
\hline & $\begin{array}{l}\text { Você acha que a situação econômica do país está melhor, } \\
\text { mais ou menos a mesma ou pior do que há um ano? (escala } \\
\text { entre } 0=\text { muito pior e } 5=\text { muito melhor) }\end{array}$ & 35,17 & 30,29 \\
\hline & $\begin{array}{l}\text { Você acha que nos próximos doze meses a situação } \\
\text { econômica do país ficará melhor, a mesma ou pior do que } \\
\text { agora? (escala entre } 0=\text { muito pior e } 5=\text { muito melhor) }\end{array}$ & 47,72 & 33,12 \\
\hline & Média do Grupo & 35,75 & 28,89 \\
\hline $\begin{array}{l}\text { Instituições do } \\
\text { regime (difuso) }\end{array}$ & $\begin{array}{l}\text { Quanto você acredita que se há progredido em reduzir a } \\
\text { corrupção nas instituições do Estado nos últimos dois anos? } \\
\text { (escala de quatro pontos entre nada }=0 \text { e muito }=4 \text { ) }\end{array}$ & 32,37 & 31,32 \\
\hline \multirow{5}{*}{$\begin{array}{l}\text { Instituições do } \\
\text { regime (específico) }\end{array}$} & $\begin{array}{l}\text { Quanta confiança o Sr. tem na ...: muita (4), alguma (3), } \\
\text { pouca (2) ou nenhuma (1)? }\end{array}$ & & \\
\hline & Poder Judicial & 36,87 & 31,07 \\
\hline & Congresso Nacional & 30,40 & 29,81 \\
\hline & Partidos Políticos & 25,03 & 27,56 \\
\hline & Média do Grupo & 30,76 & 29,48 \\
\hline \multirow{4}{*}{$\begin{array}{l}\text { Apoio ao governo } \\
\text { local }\end{array}$} & $\begin{array}{l}\text { Quanta confiança o Sr. tem na prefeitura:muita (4), alguma } \\
\text { (3), pouca (2) ou nenhuma (1)? }\end{array}$ & 38,13 & 31,06 \\
\hline & $\begin{array}{l}\text { Concorda ou discorda (escala de } 1 \text { a } 4 \text { ) que: A prefeitura } \\
\text { cumpre com suas promessas }\end{array}$ & 35,13 & 25,56 \\
\hline & $\begin{array}{c}\text { Concorda ou discorda (escala de } 1 \text { a } 4 \text { ) que: A prefeitura } \\
\text { trata a todos por igual }\end{array}$ & 38,23 & 36,13 \\
\hline & Média do Grupo & 37,16 & 30,91 \\
\hline \multirow{3}{*}{$\begin{array}{l}\text { Apoio a atores ou } \\
\text { autoridades políticas }\end{array}$} & $\begin{array}{c}\text { O Sr. aprova (1) ou desaprova a gestão do governo do } \\
\text { presidente ... }\end{array}$ & 44,87 & 49,73 \\
\hline & $\begin{array}{l}\text { Quanta confiança o Sr. tem no Presidente: muita (4), alguma } \\
\text { (3), pouca (2) ou nenhuma (1)? }\end{array}$ & 38,68 & 34,77 \\
\hline & Média do Grupo & 41,77 & 42,25 \\
\hline
\end{tabular}

Fonte: Latinobarômetro 2004.

OBS: Todas as escalas das variáveis foram recodificadas para 0-100 com a finalidade de facilitar a comparação das médias.

Em relação ao modelo de Seligson e outros, enfrentamos os seguintes problemas usando os dados do latinobarômetro:

- A maior parte das variáveis são ordinais com escalas de quatro pontos (diversamente das de Seligson que variam entre 7 e 10 pontos): algumas são binárias; 
- Em alguns casos possuímos apenas uma pergunta para testar cada dimensão;

- Não temos perguntas próprias para testar apoio local da forma como os autores em questão fizeram. Optamos então por utilizar a variável confiança na prefeitura aliada a itens que medem avaliação das prefeituras;

- Não temos como testar apoio a autoridades políticas: exceto por uma única variável com resposta binária sobre aprovação ao presidente. Sendo assim utilizaremos também confiança no presidente;

- Não podemos testar os princípios do regime da forma proposta por Seligson et alli.

- Para testar apoio difuso às instituições usamos um único item que mede progresso no combate à corrupção, idéia que está presente nas variáveis utilizadas por Seligson et alli para este fim.

Assim, estamos conscientes que a nossa aproximação não permite dialogar com os autores citados de forma completa, mas acreditamos ainda assim ser válido o contraste entre estas duas formas de operacionalizar a legitimidade, bem como esta contribuição para o mapeamento da legitimidade política na América Latina.

Inicialmente, as médias observadas na amostra reunida do latinobarômetro são mais baixas do que as observadas por Seligson et alli para o caso da Costa Rica. Mesmo considerando apenas a amostra da Costa Rica (Ver anexo II, p. XX), ainda temos médias mais baixas em relação à satisfação com a economia, confiança nas instituições políticas e o apoio ao governo local.

Não podemos testar a previsão de maior apoio difuso do que específico dado que não temos variáveis que mensurem os princípios do regime tais como propostos por Seligson et alli. Podemos apenas indicar que o apoio difuso à comunidade política medido através do orgulho nacional tem a média mais alta de todas as variáveis aqui utilizadas, sugerindo que esta parte da previsão teórica se confirma em toda a América Latina.

Abaixo apresentamos a operacionalização das dimensões da legitimidade política seguindo as orientações de Norris e análises de Kingleman e Dalton. Como já foi salientada, a principal diferença em relação à anterior é a operacionalização do apoio aos princípios centrais do regime em termos de apoio à democracia em si (ou seja, com variáveis que perguntam pelo apoio utilizando a palavra democracia). Além disso, utilizamos variáveis que medem satisfação com o funcionamento da democracia e classificação do estado da democracia no país para medir o desempenho do regime em vez da avaliação da economia utilizada por Seligson et alli. 
$\mathrm{Na}$ mensuração do apoio às instituições são incluídas outras instituições políticas como orienta Norris (1999, p.11). Por último, neste modelo não está incluída a confiança no poder local.

Tabela 2

Dimensões da Legitimidade Política - Latinobarômetro (baseadas em Norris e Dalton)

\begin{tabular}{|c|c|c|c|}
\hline Objeto de apoio & Operacionalização da Variável & Média & $\begin{array}{l}\text { Desvio } \\
\text { Padrão }\end{array}$ \\
\hline Comunidade política & $\begin{array}{c}\text { Quão orgulhoso está você de ser (nacionalidade)? (escala entre nada } \\
\text { orgulhoso = } 0 \text { e muito orgulhoso }=4 \text { ) }\end{array}$ & 85,82 & 23,07 \\
\hline \multirow{3}{*}{$\begin{array}{l}\text { Príncípios centrais } \\
\text { do regime }\end{array}$} & $\begin{array}{l}\text { Com qual das seguintes frases o Sr.(a) está mais de acordo? A democracia é } \\
\text { preferível a qualquer forma de governo (3). Em algumas circunstâncias, um } \\
\text { governo autoritário pode ser preferível a um democrático (1). Para as } \\
\text { pessoas como eu dá no mesmo um regime democrático ou um não } \\
\text { democrático(2). }\end{array}$ & 69,72 & 36,72 \\
\hline & $\begin{array}{c}\text { O Sr. está muito de acordo (4), de acordo (3), em desacordo (2) ou muito em } \\
\text { desacordo (1) com a seguinte frase: A democracia pode ter problemas, mas é } \\
\text { o melhor sistema de governo. }\end{array}$ & 65,67 & 24,86 \\
\hline & Média do Grupo & 67,69 & 30,79 \\
\hline \multirow{3}{*}{$\begin{array}{l}\text { Desempenho do } \\
\text { Regime }\end{array}$} & $\begin{array}{c}\text { Em geral você diria que está muito satisfeito (4), satisfeito (3), pouco } \\
\text { satisfeito (2) ou insatisfeito (1) com o funcionamento da democracia no } \\
\text { país? }\end{array}$ & 38,13 & 27,67 \\
\hline & $\begin{array}{c}\text { Como diria que é a democracia em seu país? Democracia plena (4), } \\
\text { democracia com pequenos problemas (3), democracia com grandes } \\
\text { problemas (2), ou não é uma democracia (1). }\end{array}$ & 39,99 & 23,08 \\
\hline & Média do Grupo & 39,06 & 25,37 \\
\hline \multirow{8}{*}{$\begin{array}{l}\text { Instituições do } \\
\text { regime }\end{array}$} & $\begin{array}{c}\text { Quanta confiança o Sr. tem na ...: muita (4), alguma (3), pouca (2) ou } \\
\text { nenhuma (1)? }\end{array}$ & & \\
\hline & Governo & 34,23 & 31,85 \\
\hline & Forças Armadas & 43,12 & 35,47 \\
\hline & Polícia & 39,31 & 32,95 \\
\hline & Poder Judicial & 36,87 & 31,07 \\
\hline & Congresso Nacional & 30,40 & 29,81 \\
\hline & Partidos Políticos & 25,03 & 27,56 \\
\hline & Média do Grupo & 34,82 & 31,45 \\
\hline \multirow{3}{*}{$\begin{array}{l}\text { Apoio a atores ou } \\
\text { autoridades políticas }\end{array}$} & O Sr. aprova (1) ou desaprova a gestão do governo do presidente ... & 44,87 & 49,73 \\
\hline & $\begin{array}{l}\text { Quanta confiança o Sr. tem no Presidente: muita (4), alguma (3), pouca (2) } \\
\text { ou nenhuma (1)? }\end{array}$ & 38,68 & 34,77 \\
\hline & Média do Grupo & 41,77 & 42,25 \\
\hline
\end{tabular}

Fonte: Latinobarômetro 2004.

OBS: Todas as escalas das variáveis foram recodificadas para 0-100 com a finalidade de facilitar a comparação das médias.

Uma primeira constatação diante das médias das variáveis que medem as dimensões da legitimidade seguindo a orientação de Norris é que a diferença em termos de apoio difuso e específico na América Latina segue o padrão que vem sendo verificado nos países centrais. Enquanto o apoio a comunidade política tem média de 85,82 e o apoio aos princípios do 
regime tem média de 67,69, as demais dimensões - mais específicas - apresentam médias bem mais baixas: 39,06 para o desempenho do regime, 34,82 para as instituições do regime e 41,77 para as autoridades políticas.

Para avaliar as duas operacionalizações do constructo da legitimidade política recorreremos inicialmente a uma análise das correlações entre os itens e, em seguida, a uma análise fatorial. Nosso intuito é verificar se o conjunto de variáveis especificadas em cada modelo refere-se aos fatores esperados.

$\mathrm{Na}$ sequência, apresentamos as tabelas de correlações entre os itens nos dois modelos. Optamos por utilizar a medida de correlação gamma uma vez que as variáveis aqui utilizadas são ordinais.

Tabela 3

Correlações (Gamma) entre as Dimensões da Legitimidade Política - América Latina

(Modelo Seligson, Both e Gómez)

\begin{tabular}{|c|c|c|c|c|c|c|c|c|c|c|c|c|c|c|}
\hline & \multicolumn{2}{|c|}{ Comunidade Política } & \multicolumn{3}{|c|}{ Desempenho do Regime } & \multirow{2}{*}{$\begin{array}{c}\begin{array}{c}\text { Instituições } \\
\text { do Regime }\end{array} \\
\text { (difuso) } \\
\text { Progresso } \\
\text { redução da } \\
\text { Corrupção }\end{array}$} & \multicolumn{3}{|c|}{ Instituições do Regime (específico) } & \multicolumn{3}{|c|}{ Apoio ao poder local } & \multicolumn{2}{|c|}{$\begin{array}{l}\text { Apoio a autoridades } \\
\text { políticas }\end{array}$} \\
\hline \multirow{2}{*}{$\begin{array}{l}\text { Comunidade } \\
\text { Política }\end{array}$} & & $\begin{array}{l}\text { Orgulho } \\
\text { Nacional }\end{array}$ & $\begin{array}{c}\text { Satisfação } \\
\text { com a } \\
\text { Economia } \\
\text { - Atual }\end{array}$ & $\begin{array}{c}\text { Satisfação } \\
\text { com a } \\
\text { Economia } \\
\text { - Passada }\end{array}$ & $\begin{array}{c}\text { Satisfação } \\
\text { com a } \\
\text { economia } \\
\text { - Futura }\end{array}$ & & $\begin{array}{l}\text { Confiança } \\
\text { no Poder } \\
\text { Judiciário }\end{array}$ & $\begin{array}{c}\begin{array}{c}\text { Confiança } \\
\text { no } \\
\text { Congresso } \\
\text { Nacional }\end{array} \\
\end{array}$ & 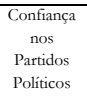 & $\begin{array}{l}\text { Confiança } \\
\text { na } \\
\text { Prefeitura }\end{array}$ & $\begin{array}{c}\text { Prefeitura } \\
\text { tem } \\
\text { tratamento } \\
\text { igual }\end{array}$ & $\begin{array}{l}\text { Prefeitura } \\
\text { cumpre } \\
\text { promessas }\end{array}$ & $\begin{array}{l}\text { Aprovação } \\
\text { do governo }\end{array}$ & $\begin{array}{l}\text { Confiança } \\
\text { no } \\
\text { Presidente }\end{array}$ \\
\hline & $\begin{array}{l}\text { Orgulho } \\
\text { Nacional }\end{array}$ & 1 & 0,065 & 0,050 & 0,094 & 0.085 & 0,091 & 0,072 & 0,057 & 0,059 & $*$ & $*$ & 0,190 & 0,122 \\
\hline \multirow{3}{*}{$\begin{array}{c}\text { Desempenho } \\
\text { do Regime }\end{array}$} & $\begin{array}{l}\text { Satisfação } \\
\text { com a } \\
\text { Economia } \\
\text { - Atual }\end{array}$ & 0,065 & 1 & 0,473 & 0,351 & 0,258 & 0,190 & 0,225 & 0,201 & 0,144 & 0,059 & 0,085 & 0,449 & 0,355 \\
\hline & $\begin{array}{l}\text { Satisfação } \\
\text { com a } \\
\text { Economia } \\
\text { - Passada }\end{array}$ & 0,050 & 0,473 & 1 & 0,426 & 0,200 & 0,127 & 0,156 & 0,134 & 0,108 & 0,033 & $*$ & 0,434 & 0,325 \\
\hline & $\begin{array}{c}\text { Satisfação } \\
\text { com a } \\
\text { economia - } \\
\text { Futura }\end{array}$ & 0,094 & 0,351 & 0,426 & 1 & 0,176 & 0,186 & 0,213 & 0,216 & 0,152 & 0,037 & 0,040 & 0,353 & 0,331 \\
\hline $\begin{array}{c}\text { Instituições } \\
\text { do Regime } \\
\text { (difuso) }\end{array}$ & $\begin{array}{l}\text { Progresso } \\
\text { redução da } \\
\text { Corrupção }\end{array}$ & 0,085 & 0,258 & 0,200 & 0,176 & 1 & 0,238 & 0,265 & 0,218 & 0,194 & 0,125 & 0,115 & 0,410 & 0,337 \\
\hline \multirow{3}{*}{$\begin{array}{l}\text { Instituições } \\
\text { do Regime }\end{array}$} & $\begin{array}{l}\text { Confiança } \\
\text { no Poder } \\
\text { Judiciário }\end{array}$ & 0,091 & 0,190 & 0,127 & 0,186 & 0,238 & 1 & 0,618 & 0,505 & 0,492 & 0,141 & 0,133 & 0,248 & 0,496 \\
\hline & $\begin{array}{c}\begin{array}{c}\text { Confiança } \\
\text { no } \\
\text { Congresso } \\
\text { Nacional }\end{array} \\
\end{array}$ & 0,072 & 0,225 & 0,156 & 0,213 & 0,265 & 0,618 & 1 & 0,615 & 0,547 & 0,172 & 0,178 & 0,311 & 0,536 \\
\hline & $\begin{array}{c}\text { Confiança } \\
\text { nos } \\
\text { Partidos } \\
\text { Políticos }\end{array}$ & 0,057 & 0,201 & 0,134 & 0,216 & 0,218 & 0,505 & 0,615 & 1 & 0,495 & 0,168 & 0,189 & 0,197 & 0,476 \\
\hline Apoio ao & $\begin{array}{c}\text { Confiança } \\
\text { na }\end{array}$ & 0,059 & 0,144 & 0,108 & 0,152 & 0,194 & 0,492 & 0,547 & 0,495 & 1 & 0,286 & 0,332 & 0,199 & 0,404 \\
\hline
\end{tabular}




\begin{tabular}{|c|c|c|c|c|c|c|c|c|c|c|c|c|c|c|}
\hline \multirow[t]{3}{*}{ poder local } & $\begin{array}{l}\text { Preféturara } \\
\end{array}$ & & & & & & & & & & & & & \\
\hline & $\begin{array}{c}\text { Prefétitura } \\
\text { tem } \\
\text { tratamento } \\
\text { igual }\end{array}$ & * & 0,059 & 0,033 & 0,037 & 0,125 & 0,141 & 0,172 & 0,168 & 0,286 & 1 & 0,676 & 0,061 & 0,098 \\
\hline & $\begin{array}{c}\text { Preféiturata } \\
\text { cumpre } \\
\text { promessas }\end{array}$ & * & 0,085 & * & 0,040 & 0,115 & 0,133 & 0,178 & 0,189 & 0,332 & 0,676 & 1 & 0,049 & 0,098 \\
\hline \multirow{2}{*}{$\begin{array}{c}\text { Apoio a } \\
\text { autoridades } \\
\text { políticas }\end{array}$} & $\begin{array}{l}\text { Aprovacaca o } \\
\text { do governo }\end{array}$ & 0,190 & 0,449 & 0,434 & 0,353 & 0,410 & 0,248 & 0,311 & 0,197 & 0,199 & 0,061 & 0,049 & 1 & 0,727 \\
\hline & $\begin{array}{l}\text { Confiança } \\
\text { no } \\
\text { Presidente }\end{array}$ & 0,122 & 0,355 & 0,325 & 0,331 & 0,337 & 0,496 & 0,536 & 0,476 & 0,404 & 0,093 & 0,098 & 0,727 & 1 \\
\hline
\end{tabular}

Fonte: Latinobarômetro 2004.

*Correlações com significância menor que 0,001 não foram incluídas na tabela.

$\mathrm{Na}$ tabela de correlações acima destacamos as correlações entre os itens que compõem cada dimensão, os quais apresentam os mais altos valores. A variável orgulho nacional, usada para medir apoio aos princípios do regime é a que apresenta os mais baixos níveis de correlação com todas as demais variáveis. Outro dado importante é o fato da aprovação do governo estar fortemente associada com a confiança no presidente, entre as diversas dimensões a do apoio a autoridades é que possui a mais forte correlação. Além disso a satisfação com a economia (usada aqui para mensurar desempenho do regime) tem forte correlação com a aprovação ao governo e a confiança no presidente (ainda que menos intensa também é das mais fortes entre as correlações).

Nossa tentativa de usar a variável progresso no combate à corrupção para mensurar apoio difuso às instituições não se mostra muito eficiente dados os baixos níveis de correlação entre ela e as demais dimensões da legitimidade com exceção da dimensão apoio a autoridades. A tabela 4 nos mostra as correlações entre os itens definidos para testar o modelo de legitimidade de Norris e Dalton. 


\section{Tabela 4}

Correlações (Gamma) entre as Dimensões da Legitimidade Política - América Latina (Modelo Norris e Dalton)

\begin{tabular}{|c|c|c|c|c|c|c|c|c|c|c|c|c|c|c|}
\hline & \multicolumn{2}{|c|}{ Comunidade Política } & \multicolumn{2}{|c|}{ Princípios do Regime } & \multicolumn{2}{|c|}{ Desempenho do Regime } & \multicolumn{6}{|c|}{ Instituições do Regime } & \multicolumn{2}{|c|}{$\begin{array}{c}\text { Apoio a autoridades } \\
\text { políticas }\end{array}$} \\
\hline \multirow[t]{2}{*}{$\begin{array}{l}\text { Comunidade } \\
\text { Política }\end{array}$} & & $\begin{array}{l}\text { Orgulho } \\
\text { Nacional }\end{array}$ & $\begin{array}{c}\text { Apoio a } \\
\text { democracia }\end{array}$ & $\begin{array}{c}\text { Apoio a } \\
\text { democracia } \\
\text { II }\end{array}$ & $\begin{array}{l}\text { Satisfação com o } \\
\text { funcionamento } \\
\text { da democracia }\end{array}$ & $\begin{array}{l}\text { Classificacăào da } \\
\text { democracia }\end{array}$ & $\begin{array}{c}\text { Confiança } \\
\text { no } \\
\text { Governo }\end{array}$ & $\begin{array}{c}\text { Confiançaa } \\
\text { nas Forças } \\
\text { Armadas }\end{array}$ & $\begin{array}{l}\text { Confiança } \\
\text { na Polícia }\end{array}$ & $\begin{array}{l}\text { Confiança } \\
\text { no Poder } \\
\text { Judiciário }\end{array}$ & $\begin{array}{c}\text { Confiança } \\
\text { no } \\
\text { Congresso } \\
\text { Nacional }\end{array}$ & $\begin{array}{c}\text { Confiança } \\
\text { nos } \\
\text { Partidos } \\
\text { Políticos }\end{array}$ & $\begin{array}{l}\text { Aprovação } \\
\text { do governo }\end{array}$ & $\begin{array}{c}\text { Confiança } \\
\text { no } \\
\text { Presidente }\end{array}$ \\
\hline & $\begin{array}{c}\text { Orgulho } \\
\text { Nacional }\end{array}$ & 1 & 0,100 & 0,108 & 0,137 & $0,034^{*}$ & 0,127 & 0,109 & 0,080 & 0,091 & 0,072 & 0,057 & 0,190 & 0,122 \\
\hline \multirow{2}{*}{$\begin{array}{l}\text { Princípios do } \\
\text { Regime }\end{array}$} & $\begin{array}{c}\text { Apoio a } \\
\text { democracia }\end{array}$ & 0,100 & 1 & 0,454 & 0,326 & 0,178 & 0,125 & $-0,077$ & 0,071 & 0,065 & 0,011 & 0,124 & 0,108 & 0,095 \\
\hline & $\begin{array}{c}\text { Apoio a } \\
\text { democracia II }\end{array}$ & 0,108 & 0,454 & 1 & 0,306 & 0,198 & 0,206 & $*$ & 0,105 & 0,013 & 0,161 & 0,157 & 0,225 & 0,189 \\
\hline \multirow{2}{*}{$\begin{array}{l}\text { Desempenho } \\
\text { do Regime }\end{array}$} & $\begin{array}{l}\text { Satisfação com o } \\
\text { funcionamento } \\
\text { da democracia }\end{array}$ & 0,137 & 0,326 & 0,306 & 1 & 0,451 & 0,395 & 0,157 & 0,224 & 0,277 & 0,301 & 0,253 & 0,410 & 0,364 \\
\hline & $\begin{array}{c}\text { Classificação da } \\
\text { democracia }\end{array}$ & $0,034^{*}$ & 0,178 & 0,198 & 0,451 & 1 & 0,265 & 0,124 & 0,162 & 0,193 & 0,222 & 0,179 & 0,265 & 0,238 \\
\hline \multirow{6}{*}{$\begin{array}{l}\text { Instituições } \\
\text { do Regime }\end{array}$} & $\begin{array}{l}\text { Confiança no } \\
\text { Governo }\end{array}$ & 0,127 & 0,125 & 0,206 & 0,395 & 0,265 & 1 & 0,427 & 0,452 & 0,442 & 0,506 & 0,445 & 0,611 & 0,723 \\
\hline & $\begin{array}{c}\text { Confiança nas } \\
\text { Forças Armadas }\end{array}$ & 0,109 & $-0,077$ & $*$ & 0,157 & 0,124 & 0,427 & 1 & 0,455 & 0,429 & 0,403 & 0,299 & 0,247 & 0,379 \\
\hline & $\begin{array}{l}\text { Confiança na } \\
\text { Polícia }\end{array}$ & 0,80 & 0,071 & 0,105 & 0,224 & 0,162 & 0,452 & 0,455 & 1 & 0,460 & 0,388 & 0,367 & 0,220 & 0,351 \\
\hline & $\begin{array}{l}\text { Confiança no } \\
\text { Poder Judiciário }\end{array}$ & 0,091 & 0,065 & 0,013 & 0,277 & 0,193 & 0,442 & 0,429 & 0,460 & 1 & 0,618 & 0,505 & 0,248 & 0,496 \\
\hline & $\begin{array}{c}\text { Confiança no } \\
\text { Congresso } \\
\text { Nacional }\end{array}$ & 0,072 & 0,011 & 0,161 & 0,301 & 0,222 & 0,506 & 0,403 & 0,388 & 0,618 & 1 & 0,615 & 0,311 & 0,536 \\
\hline & $\begin{array}{l}\text { Confiança nos } \\
\text { Partidos Políticos }\end{array}$ & 0,057 & 0,124 & 0,157 & 0,253 & 0,179 & 0,445 & 0,299 & 0,367 & 0,505 & 0,615 & 1 & 0,197 & 0,476 \\
\hline \multirow{2}{*}{$\begin{array}{c}\text { Apoio a } \\
\text { autoridades } \\
\text { políticas }\end{array}$} & $\begin{array}{l}\text { Aprovação do } \\
\text { governo }\end{array}$ & 0,190 & 0,108 & 0,225 & 0,410 & 0,265 & 0,611 & 0,247 & 0,220 & 0,248 & 0,311 & 0,197 & 1 & 0,727 \\
\hline & $\begin{array}{l}\text { Confiança no } \\
\text { Presidente }\end{array}$ & 0,122 & 0,095 & 0,189 & 0,364 & 0,238 & 0,723 & 0,379 & 0,351 & 0,496 & 0,536 & 0,476 & 0,727 & 1 \\
\hline
\end{tabular}

Fonte: Latinobarômetro 2004. *Correlações não significativas a 0,001 foram excluídas da tabela.

Analisaremos as correlações apresentadas na tabela de duas formas: primeiro a força das correlações entre os itens utilizados para mensurar cada dimensão e, posteriormente, a força da relação entre as dimensões. As dimensões princípios do regime e desempenho do regime mostram correlações fortes entre os itens. Comparando a dimensão desempenho do regime tal como mensurada por Seligson et alli e a operacionalização feita com base em Norris 
podemos concluir duas coisas. Em primeiro lugar, as duas operacionalizações têm coerência interna similar, o que se observa pelos seus índices de correlações entre os itens serem parecidos: 0,451 no caso da operacionalização com o uso das variáveis de satisfação com a democracia e 0,473, 0,451 e 0,426 no caso da outra maneira de operacionalizar usando satisfação com a economia.

Em segundo lugar, entretanto, quando analisamos a força das correlações com as demais dimensões do apoio político as correlações são mais fortes usando as variáveis de satisfação com a democracia, especialmente no caso da relação entre desempenho do regime e das instituições. $\mathrm{O}$ argumento de Seligson et alli de que o uso do termo democracia deve ser evitado devido a possível desejabilidade social nas respostas não nos parece definitivo, uma vez que a desejabilidade social ocorre em outras questões também como orgulho nacional. Para descartar as variáveis de apoio democrático e satisfação com a democracia seria necessário um teste mais robusto que demonstrasse uma alta desejabilidade social enviesando as respostas.

O segundo modelo apresentado possui maior coerência interna sendo as associações mais fortes entre desempenho do regime, instituições do regime e apoio à autoridades do regime. Infelizmente não temos como comparar aqui as associações entre as dimensões mais difusas entre os dois modelos uma vez que não pudemos testar apoio aos princípios do regime no modelo baseado em Seligson et alli.

A seguir apresentamos os resultados das análises fatoriais para os dois modelos.

Tabela 5

Modelo baseado em Seligson, Booth e Goméz

Análise Fatorial de componentes principais com rotação oblíqua (oblimin)

\begin{tabular}{|l|c|c|c|}
\hline \multirow{2}{*}{} & \multicolumn{3}{|c|}{ Componentes } \\
\cline { 2 - 4 } & 1 & 2 & 3 \\
\hline Orgulho da nacionalidade &, 117 &,- 170 &, 008 \\
Situação Econômica Atual do País &, 155 &,- 685 &, 075 \\
Situação Econômica Passada do País &, 086 &,- 729 &, 031 \\
Situação Econômica Futura do País &, 184 &,- 641 &, 032 \\
Progresso no combate à Corrupção &, 299 &,- 421 &, 127 \\
Confiança no Poder Judiciário &, 757 &,- 244 &, 088 \\
Confiança no Congresso Nacional &, 800 &,- 285 &, 133 \\
Confiança nos Partidos Políticos &, 722 &,- 220 &, 139 \\
Confiança nas Prefeituras &, 693 &,- 182 &, 351 \\
As prefeituras tratam a todos por igual &, 175 &,- 071 &, 863 \\
As prefeituras cumprem suas promessas &, 184 &,- 065 &, 870 \\
Aprovação do Governo &, 276 &,- 664 &,- 024 \\
Confiança no Presidente &, 638 &,- 626 &, 024 \\
\hline
\end{tabular}

Método de Extração: Análise de componentes principais.

Método de rotação: Oblimin com normalização Kaiser.

Fonte: Latinobarômetro 2004. 
As análises fatoriais foram feitas com rotação oblimin, uma vez que a rotação varimax foi desaconselhada por Seligson dado que a pressuposição da ortogonalidade dos fatores seria contraditória com a teoria da legitimidade.

Um primeiro resultado importante pode ser observado pelo número de fatores. No caso do modelo de Seligson et alli, a previsão seria de encontrarmos cinco fatores: desempenho do regime, apoio difuso as instituições, apoio específico as instituições, apoio ao governo local e apoio às autoridades. A dimensão comunidade política foi descartada no trabalho de Seligson et alli e também aqui aparece como não configurando uma dimensão separada das demais.

Entretanto, em vez de cinco fatores nossa análise encontrou três e com dois elementos muito claros. O primeiro deles é a existência de uma única dimensão nos itens de aprovação do governo, confiança no presidente e avaliação da situação econômica. De fato, a matriz de correlação já mostrava a força da correlação entre estes itens.

Outro ponto importante é a reunião da confiança nos partidos, congresso, judiciário e poder local em uma única dimensão. A confiança no presidente da república também pode ser avaliada como pertencente a esta dimensão.

Um último fator que aparece em nossa análise parece estar relacionado com as percepções sobre o poder local: cumprimento das promessas e tratamento igual a todos pelos funcionários das prefeituras. Sabemos que estas variáveis não são exatamente iguais às utilizadas por Seligson et alli e, uma vez mais, acreditamos que o ideal seria poder testar as diversas formulações em um só survey. Entretanto nos parece estranho que a confiança na prefeitura esteja separada desta dimensão.

Como já havíamos notado pela análise das correlações, a variável progresso no combate à corrupção se mostrou infrutífera para mensurar uma dimensão da legitimidade. Por um lado, sabemos que a sua formulação não está muito clara. Por outro, seria necessária uma bateria contendo outros itens que medissem mais propriamente o apoio difuso às instituições como a de Seligson. Sendo assim, não acreditamos que este resultado deva ser supervalorizado.

Os dois resultados que nos parece mais importante destacar aqui são:

- Itens de questionários que medem satisfação com a economia não servem para mensurar apoio ao desempenho do regime e sim para mensurar apoio aos atores ou autoridades do regime. Acreditamos que isto ocorre, pois os cidadãos relacionam o 
bom desempenho da economia a autoridades específicas: presidente, ministro da economia ${ }^{6}$.

- Com as variáveis utilizadas aqui, não encontramos o apoio ao poder local como uma dimensão separada e importante do apoio político. A confiança na prefeitura aparece como pertencendo a mesma dimensão de apoio as instituições políticas. Entretanto, esta conclusão não deve ser generalizada pois as outras variáveis utilizadas para mensurar apoio ao poder local funcionaram de maneira diversa.

A tabela 6 apresenta a análise fatorial com o modelo baseado em Norris e Dalton. Neste caso, esperávamos encontrar ao menos quatro dimensões, uma vez que Dalton também descartou o apoio à comunidade política tal como mensurado aqui pelo orgulho nacional.

Tabela 6

Modelo baseado em Norris e Dalton

Análise fatorial de componentes principais com rotação oblíqua (oblimin)

\begin{tabular}{|l|c|c|c|c|}
\hline & \multicolumn{4}{|c|}{ Componentes } \\
\cline { 2 - 5 } & 1 & 2 & 3 & 4 \\
\hline Orgulho da nacionalidade &, 059 &, 176 &,- 274 &,- 583 \\
Apoio a Democracia &, 049 &, 778 &,- 020 &,- 030 \\
Democracia pode ter problemas mas é a &, 121 &, 728 &,- 169 &,- 047 \\
melhor forma de governo & & & & \\
Satisfação com o funcionamento da &, 271 &, 505 &,- 473 &, 200 \\
democracia &, 048 &, 109 &,- 209 &, 793 \\
Classificação da democracia no País &, 581 &, 162 &,- 712 &, 009 \\
Confiança no Governo &, 622 &,- 150 &,- 306 &,- 056 \\
Confiança nas Forças Armadas &, 648 &, 056 &,- 236 &,- 022 \\
Confiança na Polícia &, 760 &, 113 &,- 242 &, 021 \\
Confiança no Poder Judiciário &, 756 &, 171 &,- 294 &, 051 \\
Confiança no Congresso Nacional &, 689 &, 199 &,- 172 &, 060 \\
Confiança nos Partidos Políticos &, 170 &, 109 &,- 841 &,- 027 \\
Aprovação do Governo &, 570 &, 140 &,- 774 &,- 010 \\
Confiança no Presidente & & & \\
\hline
\end{tabular}

Método de Extração: Análise de componentes principais.

Método de rotação: Oblimin com normalização Kaiser.

Fonte: Latinobarômetro 2004.

Neste caso, uma primeira constatação é que foram confirmados os quatro fatores previstos pela teoria: apoio às instituições do regime ( $1^{\circ}$ fator), aos princípios do regime $\left(2^{\circ}\right.$ fator), às autoridades ( $3^{\circ}$ fator) e, de forma menos clara, ao desempenho do regime.

\footnotetext{
${ }^{6}$ Como suporte a este argumento apresentamos tanto a análise fatorial quanto as correlações entre os itens.
} 
Um elemento importante é que o desempenho com o regime foi a dimensão mais insatisfatoriamente explicada tanto na operacionalização com base em Seligson et alli, quanto nesta última. Inicialmente acreditamos que a satisfação com o funcionamento da democracia no país e a classificação do estado da democracia no país (plena, parcial, inexistente) conformariam uma só dimensão. Entretanto, este último resultado nos impulsiona a buscar novas formas de operacionalização desta dimensão.

\section{Conclusão}

Nossos resultados confirmam a multidimensionalidade da legitimidade e sua divisão entre apoio difuso, com patamares mais altos em todos os países da América Latina, e apoio específico, com níveis mais baixos de apoio e maior variação.

Além disso, os dados apresentados aqui nos permitem concluir que o debate que vem sendo travado no meio acadêmico sobre a operacionalização da legitimidade política nos traz novos elementos para a compreensão do fenômeno. Diante da controvérsia entre duas formas de operacionalizar a legitimidade política, a operacionalização da legitimidade baseada nos trabalhos de Norris e Dalton nos pareceu melhor definida diante das variáveis que pudemos testar. É importante salientar que não tivemos como testar muitos dos elementos constantes na operacionalização de Seligson et alli. Os dois pontos testados com maior propriedade, o uso da bateria de itens sociotrópicos para testar desempenho do regime e o apoio local como dimensão separada da legitimidade não se mostraram válidos na amostra reunida da América Latina. Serão necessários novos testes e, especialmente, a validação desta primeira análise no conjunto da América Latina em cada contexto.

Por último gostaríamos de salientar que após uma adequada operacionalização da legitimidade política e constatação da diferença entre apoio difuso e apoio específico, cabe a pesquisa nesta área confirmar se a teoria da legitimidade está certa também quanto aos elementos que determinam cada faceta do apoio. De acordo com a teoria o apoio difuso seria moldado por experiências pessoais, socialização e aspectos ideológicos, enquanto a confiança nas instituições políticas seria mais conjuntural e dependeria da avaliação da performance das instituições.

Alguns estudos (MOISES, 2005; LOPES, 2004) já têm demonstrado que a confiança nas instituições políticas não é formada unicamente por avaliação da performance institucional, sendo fruto de uma relação onde também contam experiências pessoais em 
termos de participação e confiança interpessoal. Além disso, resta muito que investigar sobre o paradoxo do apoio político e sua relação com as mudanças sociais ou a estabilidade. Particularmente no caso latino-americano no qual a consolidação da democracia ainda enfrenta desafios, importa saber o potencial da legitimidade em possibilitar quebras da democracia ou, ao contrário, permitir suas modificações no sentido de uma democracia mais participativa, como advoga o termo cidadãos críticos. 
Tabela 7

Dimensões da Legitimidade Política no Trabalho de Seligson, Booth e Gómez (baseadas em Norris)

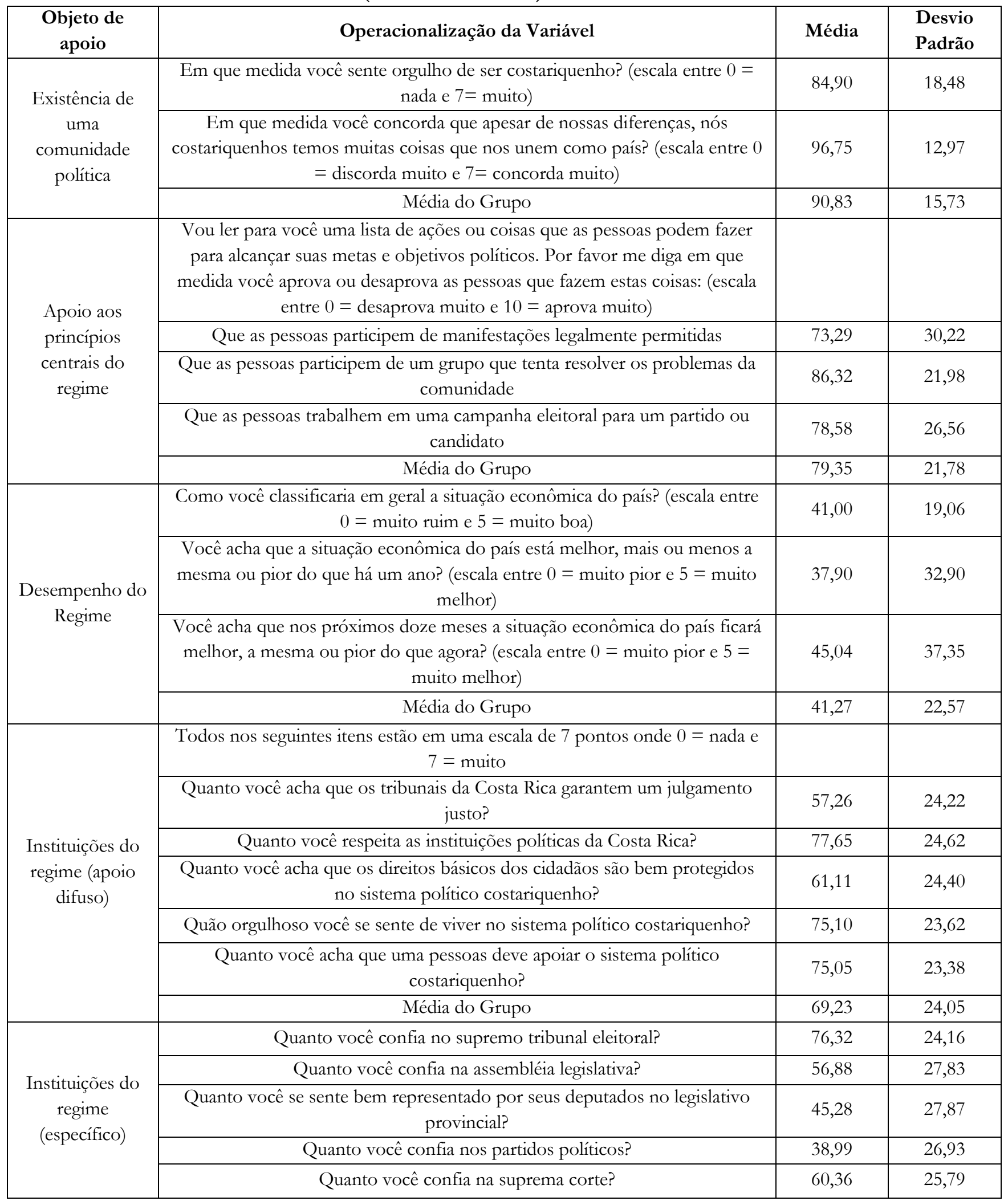




\begin{tabular}{|c|c|c|c|}
\hline & Média do Grupo & 55,59 & 19,74 \\
\hline \multirow{5}{*}{$\begin{array}{l}\text { Apoio ao } \\
\text { governo local }\end{array}$} & $\begin{array}{l}\text { Quanta confiança você tem na prefeitura? (escala de } 7 \text { pontos onde } 0=\text { nada } \\
\qquad \text { e } 7=\text { muito) }\end{array}$ & 48,86 & 26,32 \\
\hline & $\begin{array}{l}\text { Você diria que os serviços que a prefeitura oferece às pessoas de seu cantão } \\
\text { (município) são muito bons (100), bons (75), nem bons nem ruins (50), ruins } \\
\text { (25) ou muito ruins (0)? }\end{array}$ & 46,66 & 23,04 \\
\hline & $\begin{array}{c}\text { Como você acha que eles trataram você ou seus vizinhos quando vocês } \\
\text { foram a prefeitura para tratar de alguma coisa? Muito bem }(100) \text {, bem (75), } \\
\text { nem bem nem mal (50), mal (25) ou muito mal(0). }\end{array}$ & 55,73 & 22,69 \\
\hline & $\begin{array}{c}\text { Você acha que o prefeito e a câmara dos vereadores respondem aos desejos } \\
\text { das pessoas sempre(100), na maioria das vezes }(75) \text {, algumas vezes }(50) \text {, quase } \\
\text { nunca }(25) \text { ou nunca }(0) \text { ? }\end{array}$ & 34,54 & 21,53 \\
\hline & Média do Grupo & 46,44 & 23,40 \\
\hline \multirow{7}{*}{$\begin{array}{l}\text { Apoio a atores } \\
\text { ou autoridades } \\
\text { políticas }\end{array}$} & $\begin{array}{l}\text { Todos em uma escala de } 7 \text { pontos ( nada }=0 \text { e muito }=100) . \text { Falando do } \\
\text { governo de Miguel Angel Rodríguez, quanto este governo: }\end{array}$ & & \\
\hline & Lutou contra a pobreza? & 48,23 & 25,81 \\
\hline & Promoveu desenvolvimento econômico? & 52,14 & 25,46 \\
\hline & Combateu a corrupção no governo? & 42,51 & 27,40 \\
\hline & Lutou contra o crime? & 46,13 & 27,90 \\
\hline & Promoveu os princípios democráticos? & 55,18 & 24,77 \\
\hline & Média do Grupo & 45,69 & 23,15 \\
\hline
\end{tabular}

Fonte: Seligson, Booth e Goméz (2006) com base em survey realizado na Costa Rica em 2002.

OBS: Todas as escalas das variáveis usadas por Seligson, Booth e Gómez foram recodificadas para 0-100. 


\section{Referências Bibliográficas}

ALMOND, Gabriel; VERBA, Sidney. The Civic Culture. Princeton: Princeton University Press, 1963.

DALTON, Russel J. Political Support in Advanced Industrial Democracies. In: NORRIS, P. (ed).Critical citizens: global support for democratic government. Oxford: Oxford University Press, 1999. Democratic Challenges, Democratic Choices. Oxford, Oxford University Press, 2004.

EASTON, David. A systems analysis of political life. New York: Wiley, 1965.

A re-assesment of the concept of political support.British Journal of Political Science, v. 5, pp. $435-57,1975$.

LOPES, Denise M. N. N. Para pensar a confiança e a cultura política na América Latina. Opinião Pública, Campinas, vol. X, n 1, p. 162-188, 2004.

MOISÉS, José Álvaro. A desconfiança das Instituições Democráticas. Opinião Pública, XI (1), pp. 33-63, 2005.

A Avaliação das Instituições Democráticas e a Qualidade da Democracia no Brasil. Trabalho apresentado no $20^{\circ}$ Congresso Mundial da IPSA - Fukuoka, julho 8-13, 2006.

NORRIS, Pippa (ed.).Critical citizens: global support for democratic government. Oxford: Oxford University Press, 1999.

SELIGSON, Mitchel A.; BOOTH, John A.; GOMEZ, Miguel.Os Contornos da Cidadania Crítica: explorando a legitimidade democrática. Opinião Pública, Campinas, vol. 12, $\mathrm{n}^{\mathrm{o}} 1$, abril/maio, p. 01-37, 2006.

SOARES, Glaucio Ary D. Desenvolvimento Econômico e Democracia na América Latina. Dados, Rio de Janeiro, vol. 30, n. 3, p. 253-274, 1987.

ZOVATTO, Daniel. Valores, percepciones y actitudeshaciala democracia. Uma visión comparada latinoamericana: 1996-2002. América Latina Hoy, 32, 2002, p. 29-53, 2002. 